\title{
Correlates of reported modern contraceptive use among postpartum HIV- positive women in rural Nigeria: an analysis from the MoMent prospective cohort study
}

Eric E. Chinaeke', Chinenye Fan-Osuala ${ }^{2}$, Miriam Bathnna², Chamberline E. Ozigbu ${ }^{3}$, Babayemi Olakunde ${ }^{4,5}$, Habib O. Ramadhani ${ }^{6}$, Echezona E. Ezeanolue ${ }^{7,8}$ and Nadia A. Sam-Agudu ${ }^{2,6^{*}}$ (i)

\begin{abstract}
Background: Nigeria has an annual population of 200,000 women who are both pregnant and HIV-positive. High unmet need for family planning in this population could lead to unintended pregnancies, along with the increased risk of mother-to-child transmission of HIV (MTCT). To identify modifiable barriers and facilitators in effective family planning, we examined correlates of modern contraceptive use among HIV-positive women enrolled in the MoMent prevention of MTCT (PMTCT) implementation research study in rural North-Central Nigeria.

Methods: In this prospective cohort study, HIV-positive pregnant women were enrolled at 20 Primary Healthcare Centers and followed up to 12 months postpartum. Baseline socio-demographic, clinical and obstetric data were collected at enrollment. Participants were to receive routine family planning counselling from healthcare workers during postnatal visits. Analysis utilized baseline data linked to available family planning information collected from each woman at the first postpartum visit. Multivariate logistic regression was performed to determine factors associated with modern contraceptive use.
\end{abstract}

Results: Out of 497 women enrolled, family planning data was available for 399 (80.3\%) women, of whom 349 (87. 5\%) received family planning counselling, and 321 (80.5\%) were 30 years old or less. Two-thirds $(268,67.2 \%)$ of the cohort analyzed had 1-2 children at baseline; 24.8\% $(n=99)$ had 3-4 children, and 8.0\% $(n=32)$ had $>4$ children. Approximately half $(199,49.9 \%)$ of the women reported no modern contraceptive use in the postpartum period. Male condoms $(116,29.1 \%)$ were the most reported method of contraception; other methods reported included oral hormones $(71,17.8 \%)$ and intrauterine devices $(13,3.2 \%)$. Only disclosure of HIV status to male partner or relative $(\mathrm{aOR}=2.0,95 \% \mathrm{Cl}: 1.2-3.3 ; p=0.01)$ and receipt of family planning counselling $(\mathrm{aOR}=2.3,95 \% \mathrm{Cl}: 1.1-4.8$; $p=0.03$ ) were positively associated with reported modern contraceptive use. Age, marital or educational status, religious affiliation, employment status, gravidity and parity were non-correlates.

Conclusions: Family planning counselling and disclosure of HIV status are modifiable positive predictors of contraceptive use among our cohort of postpartum HIV-positive women in rural Nigeria. Rates of unintended pregnancy and concomitant risk of MTCT could be significantly reduced through strategies that facilitate these correlates.

\footnotetext{
* Correspondence: nsamagudu@ihvnigeria.org

${ }^{2}$ International Research Center of Excellence, Institute of Human Virology

Nigeria, Abuja, Nigeria

${ }^{6}$ Division of Epidemiology and Prevention, Institute of Human Virology,

University of Maryland School of Medicine, Baltimore, USA

Full list of author information is available at the end of the article
}

(c) The Author(s). 2019 Open Access This article is distributed under the terms of the Creative Commons Attribution 4.0 International License (http://creativecommons.org/licenses/by/4.0/), which permits unrestricted use, distribution, and reproduction in any medium, provided you give appropriate credit to the original author(s) and the source, provide a link to the Creative Commons license, and indicate if changes were made. The Creative Commons Public Domain Dedication waiver (http://creativecommons.org/publicdomain/zero/1.0/) applies to the data made available in this article, unless otherwise stated. 
(Continued from previous page)

Clinical trials registration: Clinicaltrials.gov registration number: NCT 01936753; registered September 3, 2013.

Keywords: Contraception behavior, Contraceptive agents, HIV, PMTCT, Rural populations, Nigeria,

\section{Plain English summary}

Family planning is important in the prevention of HIV from mothers to infants. Unplanned pregnancies among women living with HIV are more likely to result in HIV-positive babies. Nigeria has nearly 200,000 pregnant HIV-positive women delivering every year. Poor access to and use of family planning methods among these women may result in unplanned pregnancy and increased infant HIV infections. Identifying factors that influence contraceptive use can guide policy and interventions for infant HIV prevention. We assessed for factors influencing contraceptive use among 399 HIV-positive women in rural North-Central Nigeria who were newly-delivered mothers. Only $50 \%$ of these women reported using contraceptives, with condoms being the most frequently used, followed by oral contraceptive pills and lastly, intra-uterine devices. We further found that women who received family planning counselling or disclosed their HIV status to male partners or others were more likely to use contraception. Our results support the strengthening of interventions for increasing access to family planning and improving rates of disclosure among women living with HIV, especially in rural Nigeria.

\section{Background}

In 2017, there were an estimated 3.1 million people living with HIV in Nigeria, with women comprising approximately $55 \%$ of this population [1]. Nigeria has an annual population of nearly 200,000 HIV-positive pregnant women, representing the second-largest prevention of mother-to-child transmission of HIV (PMTCT) burden globally $[2,3]$. There is also a high unmet need for family planning among Nigerian women in general, with only $10.8 \%$ of married women using any form of modern contraception [4]. The female-predominance in Nigeria's HIV epidemic, large PMTCT burden and high unmet need for family planning demonstrate the need to include effective modern contraception as a component of comprehensive HIV care to women of reproductive age (MTCT) [5-7]. Additionally, Nigeria's adoption of lifelong antiretroviral therapy (ART) for PMTCT (Option B +) in 2016 [8] creates further urgency for providing effective contraception for increasing numbers of women on HIV treatment who wish to avoid unintended pregnancies.

MTCT still accounts for the majority of new child HIV infections worldwide; this applies to the estimated 36,000 Nigerian children newly infected with HIV in
2017, the highest globally [9]. Nigeria's PMTCT efforts have focused largely on increasing uptake and coverage of maternal ART [3], however, family planning counseling and provision of acceptable agents to address the contraceptive needs of women living with HIV are also paramount for successful PMTCT. For women living with HIV, family planning has the potential to delay motherhood and reduce unwanted pregnancy-consequently reducing maternal morbidity/mortality, improving child spacing and empowering them to discontinue child-bearing on reaching their desired family size [10]. Prevention of unintended pregnancies among HIV-infected women through family planning is cost-effective and could avert more new child HIV infections compared to perinatal transmission averted with antiretroviral drugs alone [10-14]. To this end, the World Health Organization (WHO) has long-recommended quality family planning as part of comprehensive PMTCT service delivery [15].

Despite the benefits and recommendations for contraception among women living with HIV, there have been historical challenges to successful implementation in Nigeria. Overall, access to, and utilization of modern contraception has been low in Nigeria, largely due to structural and individual-level barriers [16]. The Nigerian healthcare system lacks robust budgetary allocations for family planning, often leaving healthcare facilities with shortages in contraception commodities [17]. Utilization of modern contraceptives such as hormonal agents among Nigerian women is as low as $10 \%$, and nearly $30 \%$ of women interested in family planning do not have access to contraceptives [4, 16, 17]. Furthermore, according to previous studies, knowledge of contraception among Nigerian women living with HIV is high, however, level of knowledge is not commensurate with level of contraceptive use, and this appeared to be associated with high numbers of unintended pregnancies [17, 18].

While prior studies have reported low contraceptive use among Nigerian women living with HIV, the predictors of utilization or lack thereof-remain unclear. This evidence is particularly important to generate in rural areas, where utilization of maternal-child health services-including PMTCT and family planning- is especially low [19-21]. This study aims to identify key predictors of contraceptive use among post-partum women living with HIV in high HIV-burden rural communities in North-Central Nigeria. 


\section{Methods}

\section{Study design and setting}

This article presents cross-sectional data on family planning collected as part of the larger MoMent Nigeria prospective cohort study. Details of the prospective study's design, setting and site selection have been previously published [22]. Briefly, the MoMent study evaluated the impact of structured (supervised activities, standardized training and reporting tools) peer support on maternal PMTCT retention and infant presentation for early HIV diagnosis [23, 24]. It was conducted in rural and semi-rural areas of the Federal Capital Territory and Nasarawa state, located in Nigeria's North-Central region. At $5.8 \%$, the prevalence of HIV among pregnant women in this zone ranks highest in the country [25]. The North-Central zone also has the highest prevalence of HIV among the general population in rural areas, at $3.7 \%$ [25]. As of 2013, knowledge of contraceptive use in this region was $78.6 \%$ while contraceptive use was among the lowest in the country at $15.6 \%$ [20].

The MoMent study was implemented at 20 primary healthcare centers (PHCs) across the two study states. Using criteria based on duration of PMTCT service provision, ANC clinic flow, numbers of HIV-positive women identified, staff strength, and EID service availability, the 20 study sites were selected from 102 available PHCs and assigned to intervention or control arm as matched pairs [22]. These 20 PHCs were located in 20 different towns and villages spanning nine local government areas (districts) [26], and were each staffed by 4 to 6 PMTCT providers comprising largely nurse-midwives and community health extension workers.

The intervention was structured peer support, which consisted of formal baseline training, a detailed scope of work, supportive supervision by a designated supervisor, a standardized logbook for recording client interactions, periodic performance audits of peer counsellors as well as a systematic client tracking process [22]. The intervention package was compared to routine, less-supervised, less structured peer support. All study participants were followed up from enrollment up to 12 months postpartum and received routine Option B PMTCT care according to the prevailing national guidelines [27]. All participants were also expected to receive family planning counselling from healthcare workers during routine postnatal visits.

\section{Recruitment procedures}

Since this was a sub-study within the larger prospective MoMent study, the sample available for this analysis was limited to the sample recruited for the MoMent study overall. Details of the sample size calculations have been published in the protocol paper [22]. Ultimately, 497 women were recruited in the prospective study as follows: HIV-positive pregnant women were recruited from antenatal care (ANC) clinics of study PHCs to receive either structured support or routine peer support. Eligible participants were aged 15 years or more, had made a minimum of one ANC visit before delivery and planned to continue receiving antenatal and postnatal care at their PHC of recruitment [22]. Both ART-naïve and ART-experienced pregnant women (irrespective of gestational age) were recruited; those presenting in labor were excluded. HIV screening was conducted routinely for all pregnant women presenting to ANC clinics at the study sites, and women who were new or known HIV-positive were subsequently linked to a Mentor Mother (intervention sites) or routine peer counsellor (control sites) by a healthcare worker. Thereafter, study staff would approach women interested in participating in the study for informed consent. Recruitment was conducted between April 2014 and September 2015.

\section{Data collection}

Standardized case report forms were used to collect baseline and family planning data of study participants by face-to-face interviews and abstraction from medical records. Information on participants' socio-demographic, clinical and obstetric history including age, marital status, level of education, religion, employment status, parity, time of HIV diagnosis, and HIV disclosure status were collected at enrollment. As part of routine study data collection, family planning information was collected during clinic visits made by each woman within the 12-month postpartum period. Participants were asked about their contraceptive of choice and whether they received postpartum family planning counselling from their healthcare provider.

All responses were based on self-report, and no verification of contraceptive use was conducted. Data analysis was restricted to the first postpartum clinic visit where family planning data was available for collection. All study data was obtained by study staff directly from participants and/or from facility maternal-child registers.

\section{Data analysis}

Frequency and distribution of contraceptive use among study participants was described using simple proportions. The outcome of interest for the correlation analysis was modern contraceptive use which was defined as the self-reported use of one of the following modern contraceptive methods: condoms, intrauterine devices, and hormonal contraceptives, with an "other" category reserved for less-used methods such as sterilization. Reports of traditional methods such as abstinence and no method of contraception were categorized as "no modern contraceptive use". These categorizations were based 
on definitions from the United Nations Population Division [4].

To assess for correlates of contraceptive use, participants' baseline socio-demographic and obstetric data were linked to their postpartum family planning data. Analysis was restricted to women with available family planning information. Multivariate logistic regression was performed to test for variables independently associated with contraceptive use. Covariates assessed included socio-demographics (age, marital status, religion), socio-economic factors (employment status, level of education), obstetrics (parity, gravidity, contraceptive choice, receipt of family planning) and HIV care (HIV disclosure status, timing of HIV diagnosis).

For women missing family planning data due to death, loss-to-follow-up or non-response, a sensitivity analysis was performed using baseline demographic and obstetric characteristics for imputation. Variables included in the multiple imputation model were socio-demographics (age, marital status, religion), socio-economic factors (employment status, level of education), obstetrics (parity, gravidity, contraceptive choice, receipt of family planning) and HIV care (HIV disclosure status, timing of HIV diagnosis).

Results of the multivariate analysis were presented as adjusted odds ratios (aORs) with $p$-values and confidence intervals $(\mathrm{CI})$. Statistical significance was considered at $p<0.05$ and for confidence intervals excluding the value " 1 ". The analysis was performed using STATA version 12 (Statacorp, College Station, Texas).

\section{Ethical considerations}

The study was approved by the Nigerian National Health Research Ethics Committee, the Ethics Review Committee of the World Health Organization and the Institutional Review Board of the University of Maryland, Baltimore. All study participants provided written informed consent. All approvals allowed for the inclusion of participants 15 to less than 18 years of age as they were considered able to provide written informed consent for research participation due to their status as pregnant women. Safeguards against intense community-level stigma for participants included contractual requirements for Mentor Mothers to maintain client confidentiality especially with regard to HIV status, the option to arrange client visits at alternate locations if home visits were not acceptable, and use of generically-labeled Mentor Mother logbooks that did not include the term "HIV."

\section{Results}

Baseline antenatal characteristics of enrolled women

A total of 497 HIV-positive pregnant women were enrolled in the MoMent study. Two women died and 52 were lost to follow-up before delivery, leaving 443 women alive and available in the postpartum period. Of these 443 women, 399 (90.1\%) had available data on receipt or non-receipt of postpartum family planning counselling and contraceptive choice. Nearly 90\% (349/ 399) of these women received family planning counselling in the postpartum period. At the time of antenatal enrollment, $321(80.5 \%)$ of the 399 women were aged 30 years or less, 380 (95.2\%) were married, and 203 (50.9\%) had received secondary or higher-level education.

\section{Postpartum status of surveyed HIV-positive women}

Data on the post-delivery time-points at which participants were first surveyed on postpartum contraceptive use were collated. A total of 353 (88.5\%) women with family planning data available were surveyed between 0 and 3 months postpartum; $24(6.0 \%)$ were $>3$ to 6 months postpartum; $11(2.8 \%)$ were $>6$ to 9 months postpartum, and $8(2.0 \%)$ were $>9$ to 12 months postpartum; this included 5 women who were surveyed between 1 and 3 weeks beyond their 12-month postpartum date.

\section{Reported postpartum use of modern contraceptives}

Of the 399 women with available data, approximately half $(49.9 \%, 199)$ reported no contraceptive use. Among the remaining half $(n=200)$, male condoms were the most frequently reported method of contraception $(116,58.0 \%)$, followed by oral hormonal contraception $(71,35.5 \%)$ and intra-uterine devices $(13,6.5 \%)$ (Table 1$)$. There were no reports of the use of injectables, female condoms or male or female sterilization for contraception.

\section{Correlates of reported postpartum modern contraceptive use}

Multivariate analysis showed that women who had disclosed their HIV status to a male partner or relative $(\mathrm{aOR}=2.0,95 \% \mathrm{CI}: 1.2-3.3 ; p=0.01)$ or who had received family planning counselling $(\mathrm{aOR}=2.3,95 \% \mathrm{CI}$ : 1.1-4.8; $p=0.03$ ) were more likely to have reported using contraceptives than those who had not (Table 2). Parity of $>4$ trended towards, but did not achieve significance as a correlate of reported contraceptive use.

Table 1 Reported Modern Contraceptive Use among Postpartum Women Living with HIV

\begin{tabular}{ll}
\hline Contraceptive Type & $\begin{array}{l}\text { All Women }(\mathrm{N}=399) \\
\mathrm{n}(\%)\end{array}$ \\
\hline Male condoms & $116(29.1)$ \\
Oral Hormones & $71(17.8)$ \\
Intra-uterine devices & $13(3.2)$ \\
Injectable Hormones & $0(0.0)$ \\
Female condoms & $0(0.0)$ \\
Male/female sterilization & $0(0.0)$ \\
None & $199(49.9)$ \\
\hline
\end{tabular}


Table 2 Correlates of Reported Modern Contraceptive Use among Women Living with HIV

\begin{tabular}{|c|c|c|c|c|}
\hline Characteristics & $\begin{array}{l}\text { All Women } \\
N=399\end{array}$ & $\begin{array}{l}\text { Contraceptive Use } \\
\mathrm{n}(\%)^{\mathrm{a}}\end{array}$ & aOR $(95 \% \mathrm{Cl})$ & $P$ value \\
\hline \multicolumn{5}{|l|}{ Type of Peer Support } \\
\hline Routine Peer Support & $153(38.4)$ & $91(59.5)$ & 1.0 & \\
\hline Mentor Mother & $246(61.7)$ & $109(44.3)$ & $0.5(0.3-0.8)$ & $<0.01$ \\
\hline \multicolumn{5}{|l|}{ Age, years } \\
\hline$<21$ & $39(9.7)$ & $14(35.9)$ & 1.0 & \\
\hline $21-30$ & $282(70.7)$ & $148(52.5)$ & $1.5(0.6-4.0)$ & 0.37 \\
\hline$>30$ & 78 (19.6) & $38(48.7)$ & $1.5(0.7-3.2)$ & 0.34 \\
\hline \multicolumn{5}{|l|}{ Marital status } \\
\hline Married & $380(95.5)$ & $191(50.3)$ & 1.0 & \\
\hline Single $e^{b}$ & $18(4.5)$ & $9(50.0)$ & $1.1(0.4-3.1)$ & 0.83 \\
\hline \multicolumn{5}{|l|}{ Educational level attained } \\
\hline None & $106(26.6)$ & $57(53.8)$ & 1.0 & \\
\hline Primary & $90(22.5)$ & $39(43.3)$ & $0.8(0.4-1.4)$ & 0.41 \\
\hline Secondary & $164(41.1)$ & $83(50.6)$ & $0.9(0.5-1.6)$ & 0.71 \\
\hline Tertiary & $39(9.8)$ & $21(53.9)$ & $0.9(0.4-2.2)$ & 0.81 \\
\hline \multicolumn{5}{|l|}{ Religious affiliation } \\
\hline Christian & $270(67.7)$ & $132(48.9)$ & 1.0 & \\
\hline Muslim & $129(32.3)$ & $68(52.7)$ & $1.1(0.7-1.8)$ & 0.75 \\
\hline \multicolumn{5}{|l|}{ Employment status } \\
\hline Employed - skilled & $58(14.5)$ & $27(46.6)$ & 1.0 & \\
\hline Employed - unskilled & $61(15.3)$ & $39(63.9)$ & $1.9(0.9-4.2)$ & 0.09 \\
\hline Unemployed & $280(70.2)$ & $134(47.9)$ & $1.0(0.5-1.9)$ & 0.93 \\
\hline \multicolumn{5}{|l|}{ HIV disclosure status ${ }^{c}$} \\
\hline No & $101(25.3)$ & $37(36.6)$ & 1.0 & \\
\hline Yes & $298(74.7)$ & $163(54.7)$ & $2.0(1.2-3.3)$ & 0.01 \\
\hline \multicolumn{5}{|l|}{ Time of HIV diagnosis } \\
\hline Previously diagnosed & $166(41.6)$ & $95(57.2)$ & 1.0 & \\
\hline Newly diagnosed & $233(58.4)$ & $105(45.1)$ & $0.8(0.5-1.3)$ & 0.31 \\
\hline \multicolumn{5}{|l|}{ Parity } \\
\hline $0-2$ & $268(67.2)$ & $135(50.4)$ & 1.0 & \\
\hline $3-4$ & $99(24.8)$ & $54(54.6)$ & $0.9(0.5-1.6)$ & 0.71 \\
\hline$>4$ & $32(8.0)$ & $11(34.4)$ & $0.3(0.1-1.0)$ & 0.05 \\
\hline \multicolumn{5}{|l|}{ Gravidity } \\
\hline 1 & $76(19.1)$ & $34(44.7)$ & 1.0 & \\
\hline $2-4$ & $250(62.7)$ & $132(52.8)$ & $1.2(0.4-3.5)$ & 0.70 \\
\hline$>4$ & $73(18.3)$ & $34(46.6)$ & $1.1(0.6-2.0)$ & 0.87 \\
\hline \multicolumn{5}{|c|}{ Counselled on family planning } \\
\hline No & $46(11.7)$ & $15(32.6)$ & 1.0 & \\
\hline Yes & $349(88.4)$ & $181(51.9)$ & $2.3(1.1-4.8)$ & 0.03 \\
\hline
\end{tabular}

aOR, adjusted odds ratio; $\mathrm{Cl}$, confidence interval

$\mathrm{p}$ value $<0.05=$ statistically significant. Bolded aORs, $\mathrm{Cls}$ and $p$ values denote statistically significant results

${ }^{\text {a}}$ Denotes row percentage of women reporting contraceptive use

${ }^{\mathrm{b}}$ Includes single, widowed, divorced and separated women

${ }^{\mathrm{c}}$ Disclosure to male partner or relative 
Interestingly, women exposed to structured Mentor Mother support were less likely to report contraceptive use $(\mathrm{aOR}=0.5,95 \% \mathrm{CI}: 0.3-0.8, p<0.01)$. There were no associations between modern contraceptive use and the remaining variables evaluated-including education, religious affiliation or employment status.

Due to the significant amount $(98 / 497,19.7 \%)$ of missing family planning data, a sensitivity analysis was performed to verify the robustness of the results (Table 3). Here, exposure to Mentor Mother support lost statistical significance while disclosure status $(\mathrm{aOR}=2.1, \mathrm{CI}$ : 1.3-3.3; $p<0.01)$ and receipt of family planning counselling (aOR $=3.1$, CI: $1.8-5.3 ; \mathrm{p}<0.01)$ retained significance.

We further analyzed separately for correlates of the most frequently reported contraceptives: male condoms and oral hormones. Table 4 shows that when condom use was compared to no contraception, exposure to Mentor Mother support was associated with decreased odds of reported use $(\mathrm{aOR}=0.2, \mathrm{CI}: 0.1-0.4 ; \mathrm{p}<0.01)$. Conversely, women who had disclosed had higher odds of reported condom use $\mathrm{d}(\mathrm{aOR}=4.9, \mathrm{CI}: 2.3-10.6 ; p<0.01)$. For oral hormones versus none, women with more than 4 children had lower odds of reported use $(\mathrm{aOR}=0.2, \mathrm{CI}$ : $0.0-0.9$; $p=0.04$ ). Family planning counselling was not associated with reported use of either type of contraception when analyzed separately.

\section{Discussion}

Our study reports a high unmet need for family planning among postpartum women living with HIV in rural Nigeria. Results show that during the postpartum period, half of these women did not use modern contraceptives. Where modern contraception was used postpartum, male condoms had the highest uptake in our population. Receipt of family planning counselling and disclosure of HIV status were significantly associated with contraceptive use.

Our results are consistent with in-country studies, which have reported low modern contraception utilization among women living with HIV in Nigeria [17, 18]. Oyebode et al. reported that $87 \%$ of post-partum HIV-positive women in Jos, North-Central Nigeria confirmed not using any female-targeted contraception, only $37 \%$ always used male condoms, and only $38 \%$ had planned their last pregnancy [17]. From both urban and rural clinics in Zaria, North-West Nigeria, Shehu et al. reported that only $36 \%$ of post-partum HIV-positive women interviewed were using contraception, with male condoms being the most commonly-used (60\%), followed by injectables (22\%), oral hormones (10\%), female sterilization $(2.3 \%)$, and implants and intra-uterine devices at $1.1 \%$ each [18]. The predominance of reported male condom use among women in our study and others is expected, despite their lower failure rates in the prevention of unintended pregnancies [28]. Unfortunately, the uptake of more effective contraceptive methods such as male/female sterilization, implants, and intra-uterine devices is limited by multiple factors including poor knowledge, myths, misconception and fear of side effects $[29,30]$. However, unlike condoms, these methods are unable to prevent sexually-transmitted infections [28]. Even when women desire consistent condom use, gender power imbalances may affect their ability to negotiate with their partners [31-33]. The practical and socio-cultural challenges of condom use (whether alone or as dual protection) among HIV-affected couples need to be further explored, with the development of counter-strategies in mind.

Our findings also corroborate with other studies conducted in similar settings in sub-Saharan Africa, which have reported high unmet need for family planning and low modern contraceptive use among HIV-infected women in rural areas, and enumerate factors that may promote uptake of family planning in this population $[34,35]$. In these studies, unmet need for family planning ranged between 34 and 48\% [34, 35]. Poor knowledge, fear of adverse effects, lack of male partner support, unavailability and inaccessibility to contraceptive commodities or services, and cultural norms hinder the use of effective contraception among HIV-infected women [35-37].

Our study indicates that modern contraceptive use is significantly associated with receipt of family planning counselling among women living with HIV. Family planning counselling is a modifiable factor that can improve contraceptive use, which in turn may lead to significant reductions in unintended pregnancy and MTCT among women living with HIV. Our results are consistent with prior studies in other parts of sub-Saharan Africa [35, 38-41], which report that family planning counselling delivered by trained healthcare workers, especially where integrated with HIV services, improves modern contraceptive use by providing correct information and educating clients on different methods and their safety, modes of action, and effectiveness. This is important in rural areas, where there is often limited access to correct family planning information and effective contraceptive commodities [42, 43]. Interventions that focus on efficient and acceptable delivery of comprehensive family planning counselling are needed, especially in high HIV-burden rural settings where health systems are relatively weaker and missed opportunities for PMTCT may be more likely. Delivery of these services could be expanded and sustained through trained community workers or lay peer mentors to overcome the relative lack of professional healthcare workers and inadequate counselling skills that often limit provision of family planning counselling to HIV-infected women [42, 44]. 
Table 3 Correlates of Reported Modern Contraceptive Use among Women Living with HIV: Sensitivity Analysis

\begin{tabular}{|c|c|c|c|c|}
\hline Characteristics & $\begin{array}{l}\text { All Women } \\
N=497\end{array}$ & $\begin{array}{l}\text { Contraceptive Use } \\
\mathrm{n}(\%)^{\mathrm{a}}\end{array}$ & aOR $(95 \% \mathrm{Cl})$ & $P$ value \\
\hline \multicolumn{5}{|l|}{ Type of Peer Support } \\
\hline Routine Peer Support & $237(47.7)$ & $101(42.6)$ & 1.0 & \\
\hline Mentor Mother & $260(52.3)$ & $110(42.3)$ & $0.7(0.5-1.1)$ & 0.14 \\
\hline \multicolumn{5}{|l|}{ Age, years } \\
\hline$<21$ & $54(10.9)$ & $15(27.8)$ & 1.0 & \\
\hline $21-30$ & $352(70.8)$ & $156(44.3)$ & $1.5(0.8-3.1)$ & 0.23 \\
\hline$>30$ & $91(18.3)$ & $40(44.0)$ & $1.8(0.8-4.3)$ & 0.18 \\
\hline \multicolumn{5}{|l|}{ Marital status } \\
\hline Married & $472(95.0)$ & $202(42.8)$ & 1.0 & \\
\hline Single $e^{b}$ & $25(5.0)$ & $9(36.0)$ & $0.6(0.3-1.6)$ & 0.37 \\
\hline \multicolumn{5}{|l|}{ Educational level attained } \\
\hline None & $146(29.4)$ & $60(41.1)$ & 1.0 & \\
\hline Primary & $106(21.3)$ & $42(39.6)$ & $0.8(0.5-1.5)$ & 0.54 \\
\hline Secondary & $194(39.0)$ & $86(44.3)$ & $0.8(0.5-1.4)$ & 0.53 \\
\hline Tertiary & $51(10.3)$ & $23(45.1)$ & $0.8(0.4-1.6)$ & 0.47 \\
\hline \multicolumn{5}{|l|}{ Religious affiliation } \\
\hline Christian & 319 (64.2) & $137(43.0)$ & 1.0 & \\
\hline Muslim & $178(35.8)$ & $74(41.6)$ & $1.0(0.6-1.5)$ & 0.93 \\
\hline \multicolumn{5}{|l|}{ Employment status } \\
\hline Employed - skilled & $71(14.3)$ & $29(40.9)$ & 1.0 & \\
\hline Employed - unskilled & $68(13.7)$ & $40(58.8)$ & $1.9(0.9-3.8)$ & 0.09 \\
\hline Unemployed & $258(72.0)$ & $142(39.7)$ & $1.1(0.6-2.0)$ & 0.74 \\
\hline \multicolumn{5}{|l|}{ HIV disclosure status ${ }^{c}$} \\
\hline No & $129(26.0)$ & $38(29.5)$ & 1.0 & \\
\hline Yes & $368(74.0)$ & $173(47.0)$ & $2.1(1.3-3.3)$ & $<0.01$ \\
\hline \multicolumn{5}{|l|}{ Time of HIV Diagnosis } \\
\hline Previously diagnosed & $197(39.6)$ & $101(51.3)$ & 1.0 & \\
\hline Newly diagnosed & $300(60.4)$ & $110(36.7)$ & $0.7(0.5-1.1)$ & 0.13 \\
\hline \multicolumn{5}{|l|}{ Parity } \\
\hline $0-2$ & $333(67.0)$ & $144(43.2)$ & 1.0 & \\
\hline $3-4$ & $122(24.6)$ & $55(45.8)$ & $1.0(0.6-1.7)$ & 0.94 \\
\hline$>4$ & $42(8.4)$ & $12(28.6)$ & $0.5(0.2-1.3)$ & 0.15 \\
\hline \multicolumn{5}{|l|}{ Gravidity } \\
\hline 1 & $95(19.1)$ & $37(39.0)$ & 1.0 & \\
\hline $2-4$ & $303(61.0)$ & $139(45.9)$ & $0.9(0.5-1.7)$ & 0.85 \\
\hline$>4$ & 99 (19.9) & $35(35.4)$ & $0.7(0.3-1.8)$ & 0.46 \\
\hline \multicolumn{5}{|c|}{ Counselled on family planning } \\
\hline No & $107(21.5)$ & $25(23.4)$ & 1.0 & \\
\hline Yes & $390(78.5)$ & $186(47.9)$ & $3.1(1.8-5.3)$ & $<0.01$ \\
\hline
\end{tabular}

aOR, adjusted odds ratio; $\mathrm{Cl}$, confidence interval

$p$ value $<0.05=$ statistically significant. Bolded aORs, $\mathrm{Cls}$ and $p$ values denote statistically significant results

a Denotes row percentage of women reporting contraceptive use

${ }^{\mathrm{b}}$ Includes single, widowed, divorced and separated women

${ }^{\mathrm{c}}$ Disclosure to male partner or relative 
Table 4 Correlates of Reported Types of Modern Contraception Used among Women Living with HIV: Male Condoms and Oral Hormones vs No Contraception

\begin{tabular}{|c|c|c|c|c|}
\hline Characteristics & $\begin{array}{l}\text { Male Condoms } \\
\text { aOR ( } 95 \% \mathrm{Cl})\end{array}$ & $P$ value & $\begin{array}{l}\text { Oral Hormones } \\
\text { aOR }(95 \% \mathrm{Cl})\end{array}$ & $P$ value \\
\hline \multicolumn{5}{|l|}{ Type of Peer Support } \\
\hline Routine Peer Support & 1.0 & & 1.0 & \\
\hline Mentor Mother & $0.2(0.1-0.4)$ & $<0.01$ & $1.2(0.6-2.5)$ & 0.53 \\
\hline \multicolumn{5}{|l|}{ Age, years } \\
\hline$<21$ & 1.0 & & 1.0 & \\
\hline $21-30$ & $2.4(0.7-8.5)$ & 0.17 & $0.8(0.2-3.2)$ & 0.80 \\
\hline$>30$ & $1.9(0.7-5.6)$ & 0.23 & $1.1(0.4-3.1)$ & 0.93 \\
\hline \multicolumn{5}{|l|}{ Marital status } \\
\hline Married & 1.0 & & 1.0 & \\
\hline Single ${ }^{a}$ & $1.2(0.3-4.3)$ & 0.79 & $1.6(0.4-5.9)$ & 0.47 \\
\hline \multicolumn{5}{|l|}{ Educational level attained } \\
\hline None & 1.0 & & 1.0 & \\
\hline Primary & $0.6(0.3-1.6)$ & 0.34 & $0.8(0.3-1.9)$ & 0.57 \\
\hline Secondary & $1.1(0.5-2.4)$ & 0.74 & $0.9(0.4-2.0)$ & 0.71 \\
\hline Tertiary & $1.8(0.6-4.9)$ & 0.27 & $0.3(0.1-1.4)$ & 0.12 \\
\hline \multicolumn{5}{|l|}{ Religious affiliation } \\
\hline Christian & 1.0 & & 1.0 & \\
\hline Muslim & $0.6(0.3-1.4)$ & 0.24 & $1.1(0.7-1.8)$ & 0.75 \\
\hline \multicolumn{5}{|l|}{ Employment status } \\
\hline Employed - skilled & 1.0 & & 1.0 & \\
\hline Employed - unskilled & $2.0(0.7-5.4)$ & 0.17 & $2.3(0.9-6.1)$ & 0.10 \\
\hline Unemployed & $1.2(0.5-2.8)$ & 0.68 & $0.9(0.4-2.1)$ & 0.81 \\
\hline \multicolumn{5}{|l|}{ HIV disclosure status ${ }^{\mathrm{b}}$} \\
\hline No & 1.0 & & 1.0 & \\
\hline Yes & $4.9(2.3-10.6)$ & $<0.01$ & $1.0(0.5-1.9)$ & 0.97 \\
\hline \multicolumn{5}{|l|}{ Time of HIV Diagnosis } \\
\hline Previously diagnosed & 1.0 & & 1.0 & \\
\hline Newly diagnosed & $1.0(0.5-1.8)$ & 0.91 & $0.7(0.3-1.4)$ & 0.28 \\
\hline \multicolumn{5}{|l|}{ Parity } \\
\hline $0-2$ & 1.0 & & 1.0 & \\
\hline $3-4$ & $1.0(0.5-2.1)$ & 0.57 & $0.9(0.4-2.1)$ & 0.71 \\
\hline$>4$ & $0.7(0.2-2.8)$ & 0.96 & $0.2(0.0-0.9)$ & 0.04 \\
\hline \multicolumn{5}{|l|}{ Gravidity } \\
\hline 1 & 1.0 & & 1.0 & \\
\hline $2-4$ & $0.7(0.2-2.7)$ & 0.65 & $2.2(0.6-8.3)$ & 0.26 \\
\hline$>4$ & $0.9(0.4-2.1)$ & 0.82 & $0.9(0.4-2.2)$ & 0.85 \\
\hline \multicolumn{5}{|c|}{ Counselled on family planning } \\
\hline No & 1.0 & & 1.0 & \\
\hline Yes & $1.8(0.7-4.6)$ & 0.20 & $2.7(0.8-8.6)$ & 0.11 \\
\hline
\end{tabular}

$\mathrm{aOR}$, adjusted odds ratio; $\mathrm{Cl}$, confidence interval

$p$ value $<0.05=$ statistically significant. Bolded aORs, Cls and $p$ values denote statistically significant results ancludes single, widowed, divorced and separated women

${ }^{\mathrm{b}}$ Disclosure to male partner or relative 
Of note, structured peer support provided by Mentor Mothers emerged as a negative correlate of reported condom use when compared with no contraception. This is unexpected and may be due to sample size limitations; neither type of peer support was associated with reported contraceptive use in the overall sensitivity analysis. MoMent's Mentor Mother training curriculum did not focus on contraception or family planning counselling and this may explain why there is no appreciable effect.

Disclosure of HIV status to male partners and relatives was also associated with uptake of contraception in our study. Disclosure is also a modifiable factor, and this finding reflects the key role male partners play in family planning decision-making, particularly in Nigeria [45, 46]. Studies from other parts of sub-Saharan Africa have also reported lower odds of modern contraception uptake among HIV-positive women whose partners were not aware of the women's HIV status [47-49]. Despite increasing evidence on the association between HIV status disclosure and positive PMTCT outcomes [50-52], only two-thirds of HIV-positive African women disclose to their male partners [53]. Reasons for non-disclosure in this population include avoiding blame, divorce, neglect, or domestic violence [54, 55]. Recognizing the significance of disclosure and its potential impact, the WHO has recommended that assisted partner notification services be offered as part of HIV testing and care services [56]. Partner notification services and the facilitation of couples' HIV counselling and testing have been shown to improve partner disclosure $[56,57]$.

Our results further indicate that educational level, religious affiliation and employment status did not correlate with modern contraceptive use in our cohort. These findings contradict results from similar studies among HIV-positive women in other African countries [35, 38, 39]. Our findings also contradict previous studies conducted among Nigerian women in the general population. For instance, Adebowale et al. reported that married women who were more educated/earned more than their husbands or were employed were more likely to use modern contraception, whereas Muslim women were less likely to do so [58]. Ejembi et al. identified level of education as a positive predictor of modern contraceptive use among Nigerian women; Muslim religious affiliation was also a negative correlate [59].

It should be noted that our study population differs from the comparators, in that ours was a sample of $<500$ HIV-positive women in rural communities, whereas the other Nigerian reports were nationwide Demographic and Health Surveys among tens of thousands of women across both rural and urban communities. Our smaller sample size and narrow geographical scope may have limited our ability to identify religion, employment and/or education as correlates of modern contraceptive use. Within our cohort, educational status and Christian religious affiliation were positively associated with facility delivery [23], however, not for post-partum modern contraceptive use. The role of HIV-positive and/or rural status with regard to education, religion and employment as correlates of modern contraceptive use in Nigeria is unclear. This needs to be further explored. The paucity of relevant published data from our local study setting makes it challenging to assess our findings in the context of prior evidence. Of note, one study conducted among $~ 400$ HIV-positive women in Christian-dominant South-East Nigeria also reported non-correlation of education (primary vs post-primary) and religion (Catholic vs Non-Catholic) with the use of modern contraception [60].

Regardless of contradictions with some prior studies, our study has identified two modifiable factors-receipt of family planning counselling and partner HIV status disclosure-that can lead to an increase in contraceptive use among women living with HIV. Developing feasible, culturally-appropriate and sustainable strategies to deliver these interventions in rural areas will be key to closing PMTCT gaps in Nigeria and potentially, in similar high HIV-burden, limited-resource settings.

\section{Study limitations}

Our study has some limitations. Given that our data were based on respondents' self-reports, our findings may be subject to recall bias and/or invalid responses, leading to an over- or under-estimation of actual contraceptive use. This may have contributed to some of the contradictory findings to prior evidence previously discussed. We did not assess respondent's prior receipt of family planning counselling or use of contraception, which ultimately may have confounded our estimations. Lastly, we did not evaluate for changes in reported contraceptive use over an extended time during the postpartum period.

\section{Conclusions}

Family planning counselling and disclosure of HIV status were associated with uptake of modern contraception in our cohort of women in rural Nigeria. These are modifiable factors that are amenable to strengthening and scale-up at both facility and community level. In rural areas where human capital may be limited and health systems are relatively weak, task-shifting contraception and disclosure counselling to trained community health workers and laypersons may potentially facilitate expansion and sustainability of these services. Innovative, culturally-appropriate yet gender-empowered approaches to improve male partner disclosure and meet 
unmet needs for family planning among women living with HIV remain critical to improving PMTCT outcomes in high HIV-burden, resource-limited settings.

\section{Abbreviations}

AIDS: Acquired Immune Deficiency Syndrome; ANC: Antenatal Care; ART: Antiretroviral Therapy; HIV: Human Immunodeficiency Virus; MoMent: Mother Mentor; MTCT: Mother-To-Child Transmission of HIV; PHC: Primary Healthcare Center; PMTCT: Prevention of Mother-To-Child Transmission of HIV; WHO: World Health Organization

\section{Acknowledgements}

The authors wish to thank all the pregnant women living with HIV who volunteered as study participants for MoMent Nigeria. We also appreciate the efforts of the research staff who collected study data, the healthcare workers who provided care at study sites and the public health staff who supervised PMTCT service delivery in our study setting. Lastly, we thank the funders: WHO and Global Affairs Canada, for their instrumental financial support.

\section{Funding}

The MoMent Nigeria study was funded by the World Health Organization through an award for the INtegrating and Scaling up PMTCT through Implementation REsearch (INSPIRE) initiative from Global Affairs Canada. Neither WHO nor Global Affairs Canada were involved in the design of this study and collection, analysis, and interpretation of data and in writing this manuscript.

\section{Availability of data and materials}

All generated datasets used in analyzing this study are available from the corresponding author upon reasonable request.

\section{Authors' contributions}

EEC drafted the manuscript and contributed to data analysis/interpretation. CFO contributed to study implementation, data acquisition/analysis/ interpretation and manuscript drafting. MB contributed to study implementation, data acquisition/analysis and manuscript drafting. CEO and $\mathrm{BO}$ contributed to data analysis/interpretation, and drafting/critical review of the manuscript. HOR contributed to data analysis/interpretation and critical review of the manuscript. EEE contributed to data interpretation and critically reviewed the manuscript. NASA conceptualized and designed the study and contributed to study implementation, data acquisition/analysis/interpretation and drafting/critical review of the manuscript. All authors read and approved the final manuscript.

\section{Ethics approval and consent to participate}

The MoMent study was approved by the Nigerian National Health Research Ethics Committee, the Ethics Review Committee of the World Health Organization and the Institutional Review Board of the University of Maryland, Baltimore. All study participants provided written informed consent.

\section{Consent for publication}

Not applicable.

\section{Competing interests}

The authors have no competing interests to declare.

\section{Publisher's Note}

Springer Nature remains neutral with regard to jurisdictional claims in published maps and institutional affiliations.

\section{Author details}

'Department of Clinical Pharmacy and Outcome Sciences, University of South Carolina College of Pharmacy, Columbia, USA. ${ }^{2}$ International Research Center of Excellence, Institute of Human Virology Nigeria, Abuja, Nigeria. ${ }^{3}$ Department of Health Services Policy and Management, Arnold School of Public Health, University of South Carolina, Columbia, USA. ${ }^{4}$ School of Community Health Sciences, University of Nevada Las Vegas, Las Vegas, NV, USA. ${ }^{5}$ National Agency for the Control of AIDS, Abuja, Nigeria. ${ }^{6}$ Division of
Epidemiology and Prevention, Institute of Human Virology, University of Maryland School of Medicine, Baltimore, USA. 'Healthy Sunrise Foundation, Las Vegas, USA. ${ }^{8}$ Department of Paediatrics and Child Health, University of Nigeria, Enugu, Nigeria.

Received: 15 October 2018 Accepted: 20 December 2018

Published online: 08 January 2019

\section{References}

1. People Living with HIV Estimates for Nigeria: Adults (15+) Living with HIV by Sex [Internet]. 2018 [cited 28 September 2018]. Available from: http://aidsinfo. unaids.org/.

2. 2016 National Agency for the Control of AIDS: HIV Prevention Programs Fact Sheet [cited 2018 Sep 26]. Available from: https://naca.gov.ng/factsheet-hiv-prevention-program/.

3. UNAIDS. 2016 On The Fast-track To An AIDS-Free Generation [cited 2018 Oct 2]. Available from: http://www.unaids.org/sites/default/files/media_ asset/GlobalPlan2016_en.pdf.

4. United Nations Department of Economic and Social Affairs, 2018. World Contraceptive Use 2018 [cited 2018 Sep 2016]. Available from: http://www.un. org/en/development/desa/population/publications/dataset/contraception/ wcu2018.shtml.

5. Joint United Nations Programme on HIV/AIDS. 2017 [cited 2018 Sep 26]. Available from: http://www.unaids.org/sites/default/files/media_asset/2017_ data-book_en.pdf.

6. Wilkinson D, Abdool SK, Williams B, Gouws E. High HIV incidence and prevalence among young women in rural South Africa: developing a cohort for intervention trials. J Acquir Immune Defic Syndr. 2000;23(5):405-9.

7. Cowan F, Pettifor A. HIV in adolescents in sub-Saharan Africa. Curr Opin HIV AIDS. 2009:4(4):288-93.

8. National Guidelines for HIV Prevention Treatment and Care. 2016 [cited 2018 Oct 2]. Available from: http://apps.who.int/medicinedocs/documents/ s23252en/s23252en.pdf.

9. UNAIDS. 2018 Elimination of mother-to-child transmission of HIV estimates for Nigeria: adults (15+) living with HIV by sex. [cited 2018 Oct 2]. Available from: http://aidsinfo.unaids.org/.

10. Ashimi A, Amole T, Abubakar M, Ugwa E. Fertility desire and utilization of family planning methods among HIV-positive women attending a tertiary hospital in a suburban setting in northern Nigeria. Trop J Obstet Gynaecol. 2017;34(1):54.

11. Hladik W, Stover J, Esiru G, Harper M, Tappero J. The contribution of family planning towards the prevention of vertical HIV transmission in Uganda. PLoS One. 2009;4(11):e7691.

12. Reynolds HW, Janowitz B, Homan R, Johnson L. The value of contraception to prevent perinatal HIV transmission. Sex Transm Dis. 2006;33(6):350-6.

13. Reynolds HW, Janowitz B, Wilcher R, Cates W. Contraception to prevent HIVpositive births: current contribution and potential cost savings in PEPFAR countries. Sex Transm Infect. 2008:84(Suppl 2):ii49-53.

14. Halperin DT, Stover J, Reynolds HW. Benefits and costs of expanding access to family planning programs to women living with HIV. AIDS. 2009;23:S123-S30.

15. Organization WH. PMTCT strategic vision 2010-2015: preventing mother-tochild transmission of HIV to reach the UNGASS and millennium development goals: moving towards the elimination of paediatric HIV, December 2009. 2010.

16. Johnson OE. Determinants of modern contraceptive uptake among Nigerian women: evidence from the National Demographic and health survey. Afr J Reprod Health. 2017;21(3):89-95.

17. Oyebode T, Sagay A, Musa J, Ekwempu C, Agaba P, Idoko J, et al. Unmet need for contraception among human immunodeficiency virus-positive women in Jos, Nigeria: a call to integrate family planning and human immunodeficiency virus services. J HIV Human Reprod. 2016;4(1):13.

18. Shehu AU, Joshua IA, Umar Z. Knowledge of contraception and contraceptive choices among human immunodeficiency virus-positive women attending antiretroviral clinics in Zaria, Nigeria. Sub-Saharan Afri J Med. 2016;3(2):84

19. National HIV \& AIDS and Reproductive Health Survey, Nigeria 2012 Abuja [cited 2018]. Available from: file:///C:/Users/chinaeke/Downloads/narhs-plus2012.pdf.

20. National Population Commission Federal Republic of Nigeria Abuja NallR, Maryland, USA Nigeria Demographic and Health Survey 2013 [cited 2018 Oct 2]. Available from: https://dhsprogram.com/pubs/pdf/fr293/fr293.pdf. 
21. Nigerian National Bureau of Statistics, 2015. "The millennium development goals performance tracking survey report 2014," [cited 2018 Sep 26]. Available from: http://www.ng.undp.org/content/dam/nigeria/docs/MDGs/UNDP_NG_2014\%2 OMDG\%20Survey\%20Report.pdf.

22. Sam-Agudu NA, Cornelius LJ, Okundaye JN, Adeyemi OA, Isah HO, Wiwa OM, et al. The impact of mentor mother programs on PMTCT service uptake and retention-in-care at primary health care facilities in Nigeria: a prospective cohort study (MoMent Nigeria). J Acquir Immune Defic Syndr. 2014;67(Suppl 2):S132-8.

23. Sam-Agudu NA, Ramadhani HO, Isah C, Erekaha S, Fan-Osuala C, Anaba $U$, et al. The impact of structured mentor mother programs on presentation for early infant diagnosis testing in rural north-Central Nigeria: a prospective paired cohort study. J Acquir Immune Defic Syndr. 2017;75:S182-S9.

24. Sam-Agudu NA, Ramadhani HO, Isah C, Anaba U, Erekaha S, Fan-Osuala C, et al. The impact of structured Mentor mother programs on 6-month postpartum retention and viral suppression among HIV-positive women in rural Nigeria: a prospective paired cohort study. J Acquir Immune Defic Syndr. 2017;75(Suppl 2):S173-S81.

25. National HIV Seroprevalence Sentinel Survey Among Pregnant Women Attending Antenatal Clinics in Nigeria. 2014 [cited 2018 Oct 2]. Available from: https://naca.gov.ng/wp-content/uploads/2016/11/2014ANNUAL-REPORT-ON-HEALTH-SECTOR-HIV-and-AIDS-IN-NIGERIA.pdf.

26. Sam-Agudu NA, Isah C, Fan-Osuala C, Erekaha S, Ramadhani HO, Anaba U, et al. Correlates of facility delivery for rural HIV-positive pregnant women enrolled in the MoMent Nigeria prospective cohort study. BMC Pregnancy and Childbirth. 2017;17(1):227.

27. National Guidelines for Prevention of Mother-to-child Transmission of HIV. 2010 [cited 2018 Oct 2]. Available from: http://apps.who.int/medicinedocs/ documents/s19148en/s19148en.pdf.

28. Trussell J. Understanding contraceptive failure. Best Prac Res Clin Obstet Gynaecol. 2009;23(2):199-209.

29. Chigbu B, Onwere S, Aluka C, Kamanu C, Okoro O, Feyi-Waboso P. Contraceptive choices of women in rural southeastern Nigeria. Niger J Clin Pract. 2010;13(2):195-9.

30. Babalola S, John N. Factors Underlying the Use of Long-Acting and Permanent Family Planning Methods in Nigeria: A Qualitative Study 2012 [cited 2018 December 10]. Available from: http://www.respondproject.org/archive/files/4/4.1/4.1.3/Study5-2012-Factors-Underlining.pdf.

31. Haddad LB, Tang JH, Krashin J, Ng'ambi W, Tweya H, Samala B, et al. Factors associated with condom use among men and women living with HIV in Lilongwe, Malawi: a cross-sectional study. BMJ Sex Reprod Health. 2018; 44(1):1-12.

32. Madiba S, Ngwenya N. Cultural practices, gender inequality and inconsistent condom use increase vulnerability to HIV infection: narratives from married and cohabiting women in rural communities in Mpumalanga province, South Africa. 2017;10(sup2):1341597.

33. Langen $\Pi$. Gender power imbalance on women's capacity to negotiate self-protection against HIV/AIDS in Botswana and South Africa. Afr Health Sci. 2005;5(3):188-97.

34. Njuguna E, llovi S, Muiruri P, Mutai K, Kinuthia J, Njoroge P. Factors influencing the utilization of family planning services among HIV infected women in a Kenyan health facility. Intern J Reprod Contrac Obstet Gynecol. 2017;6(5):1746-52.

35. Wekesa E, Coast E. Contraceptive need and use among individuals with HIV/AIDS living in the slums of Nairobi, Kenya. Int I Gynecol Obstet. 2015;130:E31-E6.

36. Dhont N, Ndayisaba GF, Peltier CA, Nzabonimpa A, Temmerman M, Van De Wijgert J. Improved access increases postpartum uptake of contraceptive implants among HIV-positive women in Rwanda. Eur J Contracept Reprod Health Care. 2009;14(6):420-5.

37. Todd CS, Stibich MA, Laher F, Malta MS, Bastos FI, Imbuki K, et al. Influence of culture on contraceptive utilization among HIV-positive women in Brazil, Kenya, and South Africa. AIDS Behav. 2011;15(2):454-68.

38. Damian DJ, George JM, Martin E, Temba B, Msuya SE. Prevalence and factors influencing modern contraceptive use among HIV-positive women in Kilimanjaro region, northern Tanzania. Contracep Reprod Med. 2018;3(1):7.

39. Nattabi B, Li J, Thompson SC, Orach CG, Earnest J. Family planning among people living with HIV in post-conflict northern Uganda: a mixed methods study. Confl Heal. 2011;5(1):18.

40. Lopez LM, Grey TW, Chen M, Denison J, Stuart G. Behavioral interventions for improving contraceptive use among women living with HIV. The Cochrane Database Syst Rev 2016(8):Cd010243.
41. Sarnquist CC, Rahangdale L, Maldonado Y. Reproductive health and family planning needs among HIV-infected women in sub-Saharan Africa. Curr HIV Res. 2013;11(2):160-8.

42. Van Zyl C, Visser MJ. Reproductive desires of men and women living with HIV: implications for family planning counselling. Reprod BioMed Online. 2015;31(3):434-42.

43. Etokidem A, Ndifon W, Etowa J, Asuquo E. Family planning practices of rural community dwellers in cross river state, Nigeria. Niger J Clin Pract. 2017;20(6):707-15.

44. Mudiope P, Musingye E, Makumbi CO, Bagenda D, Homsy J, Nakitende M, et al. Greater involvement of HIV-infected peer-mothers in provision of reproductive health services as "family planning champions" increases referrals and uptake of family planning among HIV-infected mothers. BMC Health Serv Res. 2017;17(1):444.

45. Balogun O, Adeniran A, Fawole A, Adesina K, Aboyeji A, Adeniran P. Effect of male partner's support on spousal modern contraception in a low resource setting. Ethiop J Health Sci. 2016;26(5):439-48.

46. Ezeanolue EE, Iwelunmor J, Asaolu I, Obiefune MC, Ezeanolue CO, Osuji A, et al. Impact of male partner's awareness and support for contraceptives on female intent to use contraceptives in Southeast Nigeria. BMC Public Health. 2015;15(1):879.

47. Chibwesha CJ, Li MS, Matoba CK, Mbewe RK, Chi BH, Stringer JS, et al. Modern contraceptive and dual method use among HIV-infected women in Lusaka, Zambia. Infect Dis Obstet Gynecol. 2011;2011.

48. Adedimeji AA, Hoover DR, Shi Q, Cohen MH, Gard T, Anastos K. Differences in the nonuse of any contraception and use of specific contraceptive methods in HIV positive and HIV negative Rwandan women. AIDS Res Treatm. 2012;2012.

49. Wanyenze RK, Tumwesigye NM, Kindyomunda R, Beyeza-Kashesya J, Atuyambe L, Kansiime A, et al. Uptake of family planning methods and unplanned pregnancies among HIV-infected individuals: a cross-sectional survey among clients at HIV clinics in Uganda. J Int AIDS Soc. 2011;14(1):35.

50. Sarko KA, Blevins M, Ahonkhai AA, Audet CM, Moon TD, Gebi UI, et al. HIV status disclosure, facility-based delivery and postpartum retention of mothers in a prevention clinical trial in rural Nigeria. Int Health. 2017;9(4):243-51.

51. Onono MA, Cohen CR, Jerop M, Bukusi EA. Turan JM. HIV serostatus and disclosure: implications for infant feeding practice in rural South Nyanza, Kenya. BMC Public Health. 2014;14(1):390.

52. Naigino R, Makumbi F, Mukose A, Buregyeya E, Arinaitwe J, Musinguzi J, et al. HIV status disclosure and associated outcomes among pregnant women enrolled in antiretroviral therapy in Uganda: a mixed methods study. Reprod Health. 2017;14(1):107.

53. Tam M, Amzel A, Phelps BR. Disclosure of HIV serostatus among pregnant and postpartum women in sub-Saharan Africa: a systematic review. AIDS Care. 2015;27(4):436-50.

54. Rujumba J, Neema S, Byamugisha R, Tylleskar T, Tumwine JK, Heggenhougen HK. Telling my husband I have HIV is too heavy to come out of my mouth: pregnant women's disclosure experiences and support needs following antenatal HIV testing in eastern Uganda. J Int AIDS Soc. 2012;15(2):17429.

55. Odiachi A, Erekaha S, Cornelius L, Isah C, Ramadhani HO, Rapoport L, et al. HIV status disclosure to male partners among rural Nigerian women along the prevention of mother-to-child transmission of HIV cascade: a mixed methods study. Reprod Health. 2018;15(1):36.

56. WHO Guidelines Approved by the Guidelines Review Committee. Guidelines on HIV Self-Testing and Partner Notification. Supplement to consolidated guidelines on HIV testing services. In: Geneva: World Health Organization copyright (c) World Health Organization 2016; 2016.

57. Walcott MM, Hatcher AM, Kwena Z, Turan JM. Facilitating HIV status disclosure for pregnant women and partners in rural Kenya: a qualitative study. BMC Public Health. 2013;13:1115.

58. Stephen AA, Enoch PM. Modern contraceptive use, sex refusal, spousal difference in level of education among married women in Nigeria: are they interrelated? Intern J Human Soc Sc. 2014:4(6):217-30.

59. Ejembi CL, Dahiru T, Aliyu AA. Contextual factors influencing modern contraceptive use in Nigeria. DHS Working Papers No 120 Rockville, Maryland, USA: ICF International. 2015.

60. Ezugwu EC, Nkwo PO, Agu PU, Ugwu EO, Asogwa AO. Contraceptive use among HIV-positive women in Enugu, Southeast Nigeria. Int J Gynecol Obstet. 2014;126(1):14-7. 